\title{
Selectivity in the binding and detection of charge diffuse ions
}

\author{
David Parker*, Ritu Kataky, Patricia M. Kelly and Simon Palmer \\ Department of Chemistry, University of Durham, South Road, Durham, DH1 3LE, U.K.
}

\begin{abstract}
The selective binding of charge diffuse alkyl and arylammonium ions relies upon multiple weak interactions with a complementary synthetic receptor. Using appropriately sized lipophilic cyclodextrin derivatives, the chemoselective binding of alkylammonium ions such as dopamine, acetyl choline, guanidine, and long chain cationic surfactants may be achieved allowing their selective detection by either potentiometric or amperometric methods of analysis. Enantioselectivity in the binding of chiral $\beta$ hydroxyarylammonium ions, such as propranolol, allows chiral sensors to be developed. The selective detection of various clinically important analytes, such as imipramine, lignocaine and creatinine has also been studied.
\end{abstract}

The selective binding of charge dense metal ions is a relatively mature area of research that relies upon matching the donor atom, coordination number and geometric preferences of the cation with the structure of the ligand. For 'onium ions, such as $\mathrm{R}_{-} \mathrm{NH}_{3}{ }^{+}, \mathrm{NMe}_{4}{ }^{+}$and the guanidinium cation, $\left(\mathrm{NH}_{2}\right)_{3} \mathrm{C}^{+}$, the positive charge is delocalised over several atoms, giving a charge diffuse species. With the tetramethylammonium ion, for example, an approximate MNDO calculation indicates that $72 \%$ of the positive charge is distributed over the 12 peripheral hydrogen atoms. In seeking to bind such charge diffuse cations, therefore, particular attention must be paid to size complementarity and binding interactions to a synthetic receptor must involve multiple hydrogen bonding. Most of the published work relating to the complexation of tetraalkylammonium ions has tended to focus upon anionic cavitands in which electrostatic attraction probably dominates the binding $(1,2,3)$. With the exception of certain $\pi$ electron rich macrocyclic ligands $(4,5)$, most of the neutral ionophores that have been developed to bind ammonium ions only complex primary ammonium ions. Chiral crown ethers, for example, bind certain arylammonium ions enantioselectively $(6,7,8)$, but the chemoselectivity is modest (severe interference from $\mathrm{Na}^{+}$or $\mathrm{K}^{+}$) and $\mathrm{N}$-alkylation compromises the $\mathrm{N}-\mathrm{H}$...O hydrogen bonding.

\section{Lipophilic Cyclodextrins}

We were attracted by the properties of lipophilic cyclodextrin derivatives $(9,10)$ for the electroanalysis of a broad spectrum of 'onium ions. Neutral, lipophilic ionophores are preferred for potentiometric analysis so that cation and $\mathrm{pH}$ interference may be minimised. Such compounds are finding widespread application in chiral GC and HPLC analysis, and the parent cyclodextrins form well defined 1:1 inclusion complexes with a variety of size-matched aryl guest species. Our initial work focused on the evaluation of peralkylated cyclodextrin derivatives such as $\underline{1}, \underline{2}, \underline{3}$ and $\underline{4}$ as enantioselective ionophores

$(11,12)$. These derivatives were characterised - paying particular attention to the precise degree of alkylation - by NMR, electrospray mass spectrometric and reductive depolymerisation methods. It is interesting to note that per-O-ethyl- $\beta$-cyclodextrin is almost totally insoluble in water but is perfectly soluble in organic solvents $\left(\mathrm{CH}_{2} \mathrm{Cl}_{2}\right.$, hexane, toluene), while the per-O-methylated analogue is very water soluble. The long-chain lipophilic cyclodextrin derivatives 1 to $\underline{3}$ all form well-defined monolayers at the air-water interface, but only the 2,6-dialkylated compounds $\underline{1 \mathrm{a}}, \underline{\mathrm{b}}, \underline{2 \mathrm{a}}$ and $\underline{2 \mathrm{~b}}$ seem to form bilayers.
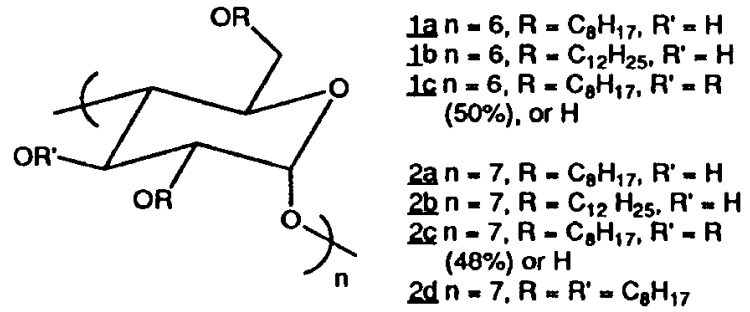

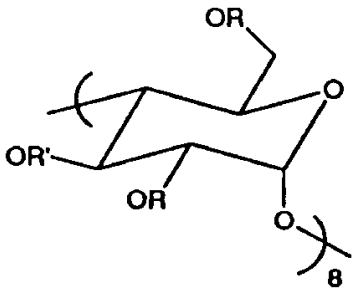

$\underline{3}$

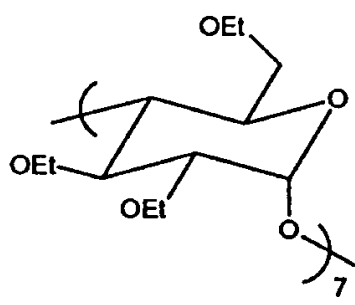

4 
Calculations of the surface area per molecule in these assemblies suggest strongly that not only are the 'primary' alkyl chains (linked to the $\mathrm{C}_{6}$ position) directed away from the aqueous phase but also that the 'secondary' chains are folded back tightly along the exterior sides of the cyclodextrin (13). At a solid surface (e.g. gold or silicon), well-defined layers have not been formed and there is clear evidence for molecular aggregation from atomic force microscopic studies: deposition of $2 \mathrm{~b}$, for example, at a clean silicon surface led to the formation of cyclodextrin aggregates varying in overall dimension from 0.1 to 2 $\mu \mathrm{m}$.<smiles>CC(C)[C@H](O)c1ccccc1</smiles>

5

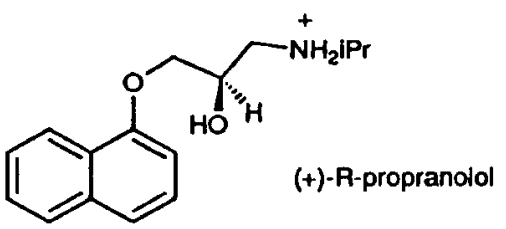

$\underline{6}$

\section{Chiral Sensors}

Judiciously selected cyclodextrin derivatives function effectively in membrane electrodes as chiral ionophores, (14). Electrode response studies with $\underline{\mathrm{lb}}$ or $\underline{1 \mathrm{c}}$, for example, allow the selective detection of $(-)-1 \mathrm{R}, 2 \mathrm{~S}$-ephedrine, $\mathbf{5}$, in the presence of its three stereoisomers and in a simulated clinical electrolyte background. The electrode has been calibrated to read-out enantiomeric purity directly, although the difference in e.m.f. response between $100 \%$ and $0 \%$ e.e. of the (-)ephedrinium ion $(26 \mathrm{mV})$ corresponds to a free energy difference in binding the two enantiomers of only $2.5 \mathrm{~kJ} \mathrm{~mol}^{-1}$. Similar differences in the free energy of binding of the diastereoisomeric host-guest complexes were also measured with propranolol using the larger $\beta$-cyclodextrin ionophores $\underline{2 b}$ and $\underline{2 c}$. Proton NMR relaxation rate measurements of the diastereoisomeric complexes of ephedrine and its deoxy and primary ammonium ion analogues with $1 \mathrm{c}$, indicate a difference in the degree of hydrogen bonding between the guest and the cyclodextrin (i.e. $+$

NH...O). Differences in the free-energy of binding of the order of $2.5 \mathrm{~kJ} \mathrm{~mol}^{-1}$ have been attributed to a single hydrogen-bond mismatch (15) in DNA binding to minor-groove intercalates. Stereodifferentiation in the cyclodextrin complexes of the ephedrinium ion arises from the preferred location in the more stable complex of the C-methyl group away from the cyclodextrin $H(3)$ and $H(5)$ protons (14).

\section{Onion Ion Detection}

The guanidinium ion forms a 1:1 complex with $\underline{2 b}$, as revealed by a ${ }^{1} \mathrm{H}$ NMR titration and by the observation of the cyclodextrin complex by positive ion electrospray mass spectrometry (16). Several cations containing the guanidine moiety may be analysed, Table 1 , including metformin, 7 , which has been used as a drug to treat diabetes mellitus. In the mass spectrum of its $1: 1$ complex with 2,6 -didodecyl$\beta$ - cyclodextrin, Fig. 1, the presence of 214 carbon atoms in the complex gives rise to a significant isotope pattern. The independence of the observed electrode response to the structure of the sensing cyclodextrin ( $\alpha$ vs $\beta, O H$ versus $O$-alkyl groups) suggested that the primary binding interaction involved NH...O(CD) hydrogen bonding. Similar characteristics were noted in the detection of the much less basic cation, creatinine $\underline{8}\left(\mathrm{pK}_{\mathrm{a}}=4.75\right)$. The concentration in serum of this clinically important metabolite (humans excrete ca. $2 \mathrm{~g}$ daily) is a sensitive function of renal behaviour. The electrode response of creatinine at low concentrations may be corrected to allow for the dissociation of this weak acid, Fig. 2, (17).

TABLE 1. Response of ISEs incorporating 2,6-didodecyl- $\beta$-cyclodextrin to organic onium ions in the absence and presence of interfering ions. Selectivity coefficients for interferent ions are given as $-\log \mathrm{k}_{\mathrm{i}, \mathrm{j}}^{\text {pot }}\left(0.1 \mathrm{~mol} \mathrm{dm}^{-3}, 310 \mathrm{~K}\right)$

\begin{tabular}{llllllll}
\hline analyte & calibration & \multicolumn{3}{c}{ interferent } & & \\
\cline { 2 - 7 } & slope/mV & $\begin{array}{l}\text { detection limit/ } \\
\text { mol dm }\end{array}$ & $\begin{array}{l}\text { clinical } \\
\text { background }\end{array}$ & $\mathrm{Na}^{+}$ & $\mathrm{K}^{+}$ & $\mathrm{NH}_{4}^{+}$ & $\mathrm{Ca}^{2+}$ \\
\hline guanidine $^{\mathrm{b}}$ & 60.2 & $10^{-5.7}$ & 2.7 & 2.9 & 1.4 & 1.75 & 3.9 \\
metformin & 61.4 & $10^{-5.6}$ & 3.1 & 3.3 & 2.5 & 2.4 & 4.3 \\
arginine & 60.2 & $10^{-4.8}$ & 0.6 & & & & \\
creatinine $^{\mathrm{b}}$ & 57.4 & $10^{-5.0}$ & 2.7 & & & & \\
\hline
\end{tabular}

a) pKpot values were determined in a simulated clinical background $\left(\mathrm{c} / \mathrm{mmol} \mathrm{dm}^{-3} \mathrm{Na}^{+} 145 ; \mathrm{K}^{+}, 4.3\right.$; $\left.\mathrm{Ca}^{2+} 1.26 ; \mathrm{Mg}^{2+} 0.9\right)$.

b) similar behaviour was noted with 2,6-di-octyl $\alpha, 2,3,6$-tri-octyl- $\beta$ and 'poly'-octyl- $\alpha$ cyclodextrin as the sensing ionophore. 


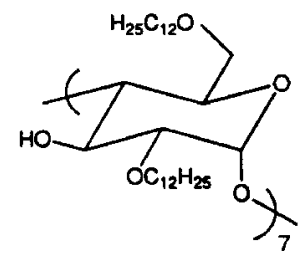
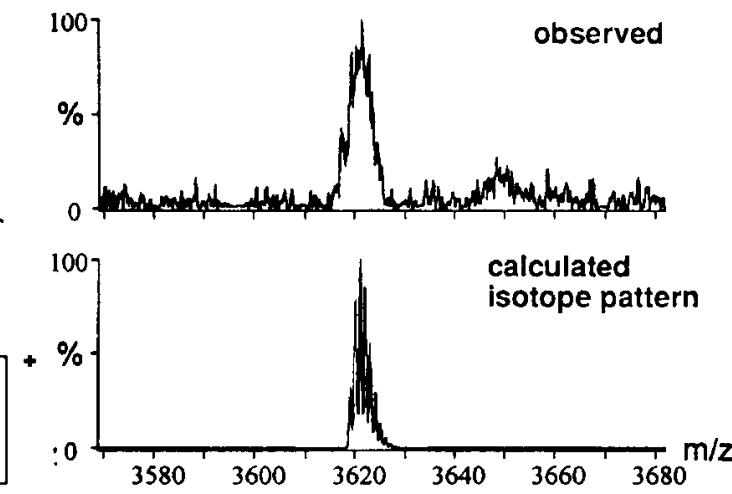<smiles>CN(C)C(=N)NC(=N)N</smiles>

$\mathbf{Z}$<smiles>[R]C(C[N+](C)([O-])[O-])OC(C)=O</smiles>

9 a) $R=H$ b) $R=M e$<smiles>CN1CC(=O)NC1=N</smiles>

a<smiles>C[N+](C)(C)CCO</smiles>

10

Fig. 1. Positive ion electrospray mass spectrum of the 1:1 complex of metformin, 7 , and 2,6-didodecyl- $\beta$-cyclodextrin.

The tetramethyl and tetraethylammonium ions have ionic diameters that are matched closely to the size of a peralkylated cyclodextrin (18). They form 1:1 complexes with $\underline{1 c}$ and $\underline{2 b}$, for example, which may be detected by potentiometric methods down to sub-micromolar concentrations. The structurally related ions acetyl choline, $9 \mathrm{a}$, methacholine $9 \mathrm{~b}$ and choline itself, 10 , may also be sensitively assayed, Table 2, with very little interference from hard cations, such as $\mathrm{Ca}^{2+}, \mathrm{Na}^{+}, \mathrm{K}^{+}$, and relatively little perturbation from the presence of protein $\left(40 \mathrm{gdm}^{-3}\right)$, Fig. 3. Such features augur well for the direct analysis of samples taken from bodily fluids.

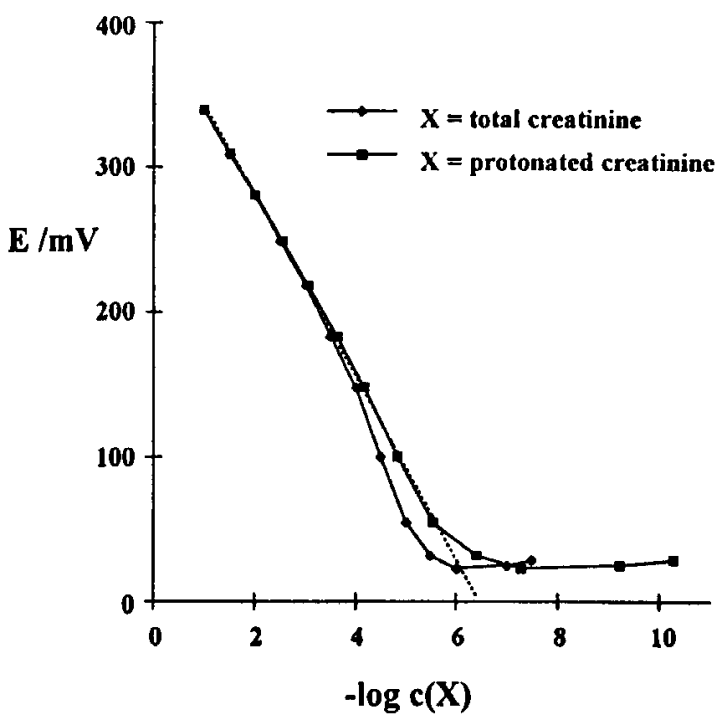

Fig. 2. Response of electrode based on 2,6-didodecyl- $\beta$-cyclodextrin to creatinine hydrochloride solutions. Protonated creatinine values are corrected for dissociation

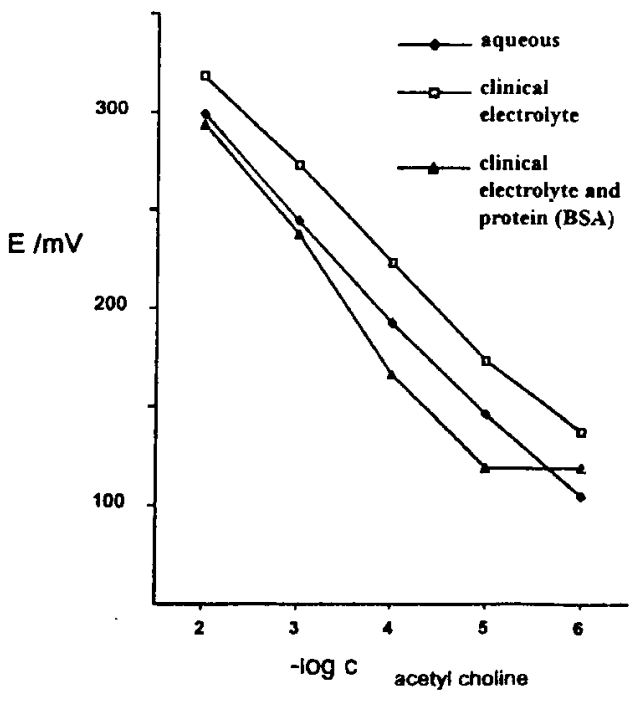

Fig. 3. Response of electrode based on 2,6- didodecyl- $\beta$-cyclodextrin to acetyl choline chloride solutions in water, simulated clinical electrolyte and in the presence of protein $\left(40 \mathrm{gdm}^{-3}\right)$

TABLE 2. Response of ISEs to 'choline' cations in the absence and presence of interferent ions, using plasticised PVC-based membrane electrodes ${ }^{\mathrm{a}}(310 \mathrm{~K})$

\begin{tabular}{llllll}
\hline analyte & ionophore & slope/mV & $\begin{array}{l}\text { detection limit' } \\
\text { mol dm }\end{array}$ & $\mathrm{pK}_{\text {pot }}^{\text {clin }}$ & $\mathrm{pK}_{\text {choline }}^{\text {pot }}$ \\
\hline acetyl choline & 'poly'-octyl- $\alpha$ & 61.5 & 6.5 & 4.2 & 1.2 \\
choline & 'poly'-octyl- $\beta$ & 60.1 & 5.1 & 4.1 & 1.8 \\
methacholine & 'poly'-octyl- $\alpha$ & 61.4 & 6.4 & 3.4 & - \\
& 'poly'-octyl- $\alpha$ & 60.3 & 6.7 & 4.4 & - \\
\hline
\end{tabular}

a) pKpot values were determined in a simulated clinical background, and the interferent choline concentration was $0.1 \mathrm{~mol} \mathrm{dm}^{-3}$. 
TABLE 3. Response of ISEs to long chain trimethylalkylammonium ions, $\mathrm{C}_{n} \mathrm{H}_{2 n+1} \mathrm{NMe}_{3}+\mathrm{Cl}^{-}$in electrodes using dioctyl sebacate as the plasticiser and 'poly'-octyl- $\beta$-cyclodextrin as the ionophore ( $298 \mathrm{~K}$ ). Data were measured at surfactant concentrations below the critical micelle concentration.

\begin{tabular}{|c|c|c|c|c|c|}
\hline & $\mathrm{C}_{8}$ & $\mathrm{C}_{10}$ & $\overline{C_{12}}$ & $\mathrm{C}_{14}$ & $C_{16}$ \\
\hline slope/mV & 59.6 & 58.6 & 58.4 & 58.8 & 58.6 \\
\hline detection limit $/ \mathrm{mol} \mathrm{dm}^{-3}$ & $10^{-6.1}$ & $10^{-6.1}$ & $10^{-6.6}$ & $10^{-6.2}$ & $10^{-6.6}$ \\
\hline pKpot & 4.7 & 4.8 & 5.2 & 4.8 & 4.5 \\
\hline$x^{2}+x^{2}$ & 4.6 & 5.4 & 5.3 & 4.9 & 4.9 \\
\hline $\begin{array}{l}\text { critical micelle concentration/ } \\
\text { mol dm}^{-3}\end{array}$ & 0.14 & 0.07 & 0.016 & $3.6 \times 10^{-3}$ & $9.2 \times 10^{-4}$ \\
\hline
\end{tabular}

Binding in the complexes of these ions must involve ionic $\mathrm{CH}$... $\mathrm{O}$ hydrogen bonds. Whilst much has been said about the binding of these ions to $\pi$-rich aromatics, gas phase mass spectrometric studies of the complexes of $\mathrm{NR}_{4}{ }^{+}$with $\mathrm{H}_{2} \mathrm{O}, \mathrm{ROH}, \mathrm{Bu}_{2} \mathrm{O}, \mathrm{Me}_{2} \mathrm{CO}$ and polyethers strongly indicate the donation of ether oxygen lone pair electron density is significantly more energetically favourable $(19,20)$. Attractive C-H...O contacts may seem unusual, but in a recent Cambridge database analysis 9 out of 10 of the shortest measured $\mathrm{C}-\mathrm{H}$...O distances involved $[\mathrm{NCH}]^{\delta+}$ as the hydrogen donor (21). Particularly short C-H...O bonds have also been shown to be a characteristic feature of cyclodextrin inclusion complexes, with C...O separations as short as $2.39 \AA$ defined crystallographically (22). Multiple, weak C-H...O bonds may make up a significant proportion, therefore, of the overall free energy of 'onium ion complexation. Long chain trimethylammonium ions may also be detected sensitively at sub-micellar concentrations $(17,23)$. Selectively over interferent $\mathrm{Na}^{+} / \mathrm{K}^{+}$ions peaks at a chain length of 10 to 12 carbon atoms, Table 3, and 1:1 complexes have been observed by electrospray mass spectrometry between $\mathrm{C}_{12} \mathrm{H}_{25} \mathrm{NMe}_{3}{ }^{+}$and 2,6-didodecyl- $\beta$-cyclodextrin .

\section{Applications in Clinical Analysis}

Dopamine, 11 , is an important neurotransmitter whose concentration in cerebrospinal fluid is of great interest to clinicians treating patients with Parkinson's disease by administering the amino-acid precursor L-Dopa. The concentration in such fluids is low $\left(10^{-6}\right.$ to $\left.10^{-7} \mathrm{~mol} \mathrm{dm}^{-3}\right)$ and at such levels<smiles>[NH3+]CCc1ccc(O)c(O)c1</smiles>

11

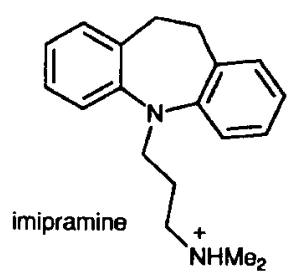

12

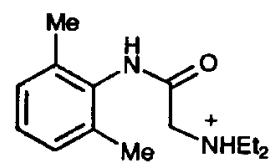

lignocaine

13

detection is better undertaken using voltammetric methods of analysis, such as differential pulse voltammetry. A screen-printed carbon electrode has been coated with 2,3,6-triethyl- $\beta$-cyclodextrin and concentrations as low as $10^{-11} \mathrm{~mol} \mathrm{dm}-3$ may be detected, monitoring the catecholamine oxidation at ca. $+200 \mathrm{mV}$ (vs. Ag/AgCl). The sterically bulkier analyte imipramine, an anti-depressant drug with a toxic level in blood of $5 \mathrm{\mu gml}^{-1}$, is more effectively sensed using a 'poly'-octyl- $\gamma$-cyclodextrin based sensor. Sub-nanomolar limits of detection were observed by differential pulse voltammetry, monitoring oxidation at $+800 \mathrm{mV}$ (vs. S.Ce). The trialkylammonium salt, lidocaine (or lignocaine) is a widely used anaesthetic with a typical serum concentration of $0.75 \mathrm{mmol} \mathrm{dm}-3$. Using 2,6 -didodecyl- $\beta$-cyclodextrin as the sensing ionophore, a nernstian response was found down to $10^{-5.6} \mathrm{~mol} \mathrm{dm}^{-3}$ concentrations. Addition of glycine $\left(10 \mathrm{mmol} \mathrm{dm}^{-3}\right)$, nicotinamide $\left(1 \mathrm{mmol} \mathrm{dm}^{-3}\right)$ and vitamin B-1 $\left(10 \mathrm{mmol} \mathrm{dm}{ }^{-3}\right)$ did not significantly impair the selective response. Addition of histidine $\left(10 \mathrm{mmol} \mathrm{dm}{ }^{-3}\right)$ lowered the slope and limit of detection significantly (to $8 \times 10^{-4} \mathrm{~mol} \mathrm{dm}^{-3}$ ), however. As the concentration of these interferents in whole blood is relatively low (his: $0.1 \mathrm{mmol} \mathrm{dm}^{-3}$; gly: $0.25 \mathrm{mmol} \mathrm{dm}-3$; vitamin $\mathrm{B}-120 \mu \mathrm{g} \mathrm{dm}^{-3}$ and nicotinamide $5 \mathrm{mg} \mathrm{dm}^{-3}$ ), the detection of the anaesthetic in serum samples is still viable, particularly as protein interference (human serum albumin, $\alpha$-glycoprotein) and inorganic cation interference (145 mmol dm-3 $\mathrm{Na}^{+}, 4.3 \mathrm{mmol} \mathrm{dm}^{-3} \mathrm{~K}^{+}, 1.26 \mathrm{mmol} \mathrm{dm}^{-3} \mathrm{Ca}^{2+}$ ) does not limit the working range of the electrode beyond the target threshold concentration, (24).

In summary, the neutral, lipophilic cyclodextrin derivatives offer considerable scope for the chemoselective detection of a variety of aryl and alkylammonium ions. Work is underway to couple these ionophores to other sensory systems, e.g. a biosensor for choline using the enzyme choline oxidase, and synthetic luminescent sensors involving conjugation to an energy-matched emissive lanthanide complex. 


\section{REFERENCES}

1. F, Vogtle, T. Merz and H. Wirtz, Angew. Chem. Int. Ed. Engl., 24, 221 (1985).

2. H.J. Schneider, T. Schiestel and P. Zimmermann, J. Amer. Chem. Soc., 114, 7698 (1992).

3. R. Meric, J.-P. Vigneron and J-M. Lehn, J. Chem. Soc. Chem. Commun., 129 (1993).

4. D.A. Stauffer and D.A. Dougherty, Tetrahedron Lett., 29, 6039 (1988).

5. A. Collet, J-P. Dutasta, B. Lozach and J-P. Chauvet, Abstr. Int. Symp. Macrocyclic Chem., 16, KL21 (1991).

6. S.C. Peacock and D.J. Cram, J. Chem. Soc. Chem. Commun., 282 (1976).

7. V. Prelog and D. Bedekovic, Helv. Chim. Acta, 62, 2285 (1979).

8. W. Bussmann, J-M. Lehn, U. Oesch, P. Plumère and W. Simon, Helv. Chim. Acta, 64, 557 (1981).

9. P.S. Bates, R. Kataky and D. Parker, J. Chem. Soc. Chem. Commun., 153 (1992).

10. P.S. Bates, R. Kataky and D. Parker, Analyst, 117, 1313 (1992).

11. P.S. Bates, D. Parker and A.F. Patti, J. Chem. Soc. Perkin Trans. 2, 657 (1994).

12. P.S. Bates, B.N. Green and D. Parker, J. Chem. Soc. Chem. Commun., 693 (1993).

13. M.H. Greenhall, P. Lukes, R. Kataky, N.E. Agbor, J.P.S. Badyal, J. Yarwood, D. Parker and M.C. Petty, Langmuir, accepted for publication (1995).

14. P.S. Bates, R. Kataky and D. Parker, J. Chem. Soc. Perkin Trans. 2, 669 (1994).

15. G.C. Best and P.B. Dervan, J. Amer. Chem. Soc., 117, 1187 (1995).

16. R. Kataky, P.M. Kelly, D. Parker and A.F. Patti, J. Chem. Soc. Perkin Trans. 2, 2381 (1994).

17. P.M. Kelly, R. Kataky, D. Parker and A.F. Patti, J. Chem. Soc. Perkin Trans. 2, submitted.

18. F. Cramer, W. Saenger and H-C. Spatz, J. Amer. Chem. Soc., 89, 14 (1967).

19. C.A. Deakyne and M. Meot-Ner, J. Amer. Chem. Soc., 107, 474 (1985).

20. M. Meot-Ner and C.A. Deakyne, J. Amer. Chem. Soc., 107, 469 (1985).

21. O. Kennard, Supramol. Chem., 1, 277 (1993).

22. T. Steiner and W. Saenger, J. Amer. Chem. Soc., 114, 10146 (1992).

23. P.S. Bates, R. Kataky and D. Parker, J. Chem. Soc. Chem. Commun., 691 (1993); P.S. Bates, R. Kataky and D. Parker, Analyst, 117, 181 (1994).

24. R. Kataky, S. Palmer and D. Parker, unpublished observations. 